\title{
DIH-HERO: Digital Innovation Hubs in Health Care Robotics
}

\author{
Compiled by: Giuseppe Riva, $\mathrm{PhD}{ }^{1,2}$ and Eleonora Riva, $\mathrm{PhD}^{3}$
}

This column will try to describe the characteristics of current cyberpsychology research in Europe. In particular, CyberEurope aims at describing the leading research groups and projects running on the other side of the Ocean.

$\mathbf{T}$ He CONSORTIUM Aims to establish an independent platform meant to connect businesses, knowledge institutes, investors, and other stakeholders, and to facilitate collaboration and support them to make their products and services in the field of robotics available to health care providers.

The European Commission has invested $€ 16$ million in DIH-HERO (Digital Innovation Hubs in Healthcare Robotics; https://dih-hero.eu/), a European project that aims to boost innovation and implementation of robotics in health care. The project consortium, which is led by the University of Twente (as coordinator), consists of 17 partners spread across 10 European countries.

The University of Twente has a leading role in this project and coordinates the activities of the European network. Stefano Stramigioli, professor in robotics at the University of Twente and coordinator of the pan-European network, explains: "The route for embedding medical innovations in clinical practice is tough, time-consuming, and requires substantial investments. It involves clinical testing, developing efficient production methods, reaching investors, establishing a company, and handling distribution, just to mention a few steps. Furthermore, multiple actors are working on various innovations in robotics. Within DIH-HERO, we can make sure that these strengthen and supplement each other where possible.'

\section{Innovation in Robotics for Health Care}

The European Commission aims to accelerate this "innovation cycle" throughout the entire value chain, making sure that the products and services are developed efficiently by connecting the relevant stakeholders. Each of the 17 partners within the consortium represents a network of health-care and knowledge institutes, investors, and commercial businesses active in robotics for health care.

While lobbying for the project, the university received important help from the Top Sector Life Sciences \& Health (LSH) of the Dutch Ministry of Economic Affairs and the province of Overijssel in the form of letters of support. Eddy van Hijum, deputy for the Economy of the province of
Overijssel portfolio, explains: "Overijssel gladly joins the DIH-HERO project for multiple reasons. We believe in the importance of robotics in health care and see this project as a great way to boost innovation in this area. We expect a lot from the cooperation between education, research, and entrepreneurs. Together, we can put forth initiatives to ensure that patients profit faster from the many advantages that the application of robotics in health care will yield.'

\section{Sharing Knowledge}

By joining forces, the plan is to build up a DIH-HERO platform during the next 4 years. This platform will add significant value throughout the entire value chain in the health care ecosystem by sharing knowledge, connecting the right stakeholders, and stimulating tailored investments.

"We are convinced that DIH-HERO can make a real difference concerning innovation in health care and will add significant value throughout the value chain, striving to bring excellent products and services to the market, to the best benefit of the end-consumer-the patient," Stramigioli concludes.

Address correspondence to: Dr. Giuseppe Riva Department of Psychology Catholic University of Milan Largo Gemelli 1-20123 Milan Italy

E-mail: giuseppe.riva@unicatt.it

Dr. Eleonora Riva Department of Cultural Heritage and Environment University of Milan Milan Italy

E-mail: eleonora.riva@unimi.it

Sources: Cordis, European Commission and European Union

\footnotetext{
${ }^{1}$ Department of Psychology, Catholic University of Milan, Milan, Italy.

${ }^{2}$ Applied Technology for Neuro-Psychology Lab, Istituto Auxologico Italiano, Milan, Italy.

${ }^{3}$ Department of Cultural Heritage and Environment, University of Milan, Milan, Italy.
} 